\title{
Pre-existing diabetes and breast cancer prognosis among elderly women
}

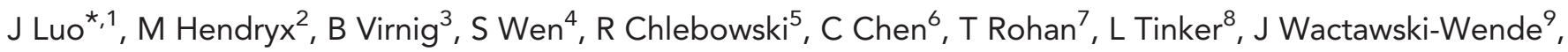
L Lessin ${ }^{10}$ and K L Margolis ${ }^{11}$

${ }^{1}$ Department of Epidemiology and Biostatistics, School of Public Health, Indiana University Bloomington, Bloomington, IN, USA; ${ }^{2}$ Department of Applied Health Science, School of Public Health, Indiana University Bloomington, Bloomington, IN, USA; ${ }^{3}$ Division of Health policy \& Management, School of Public Health, University of Minnesota, Minneapolis, MN, USA; ${ }^{4}$ Department of Biostatistics, School of Public Health, West Virginian University, Morgantown, WV, USA; ${ }^{5}$ Los Angeles Biomedical Research Institute at Harbor-University of California, Los Angeles Medical Center, Torrance, CA, USA; ${ }^{6}$ Program in Epidemiology, Division of Public Health Sciences, Fred Hutchinson Cancer Research Center, Seattle, WA, USA; ${ }^{7}$ Department of Epidemiology \& Population Health, Albert Einstein College of Medicine, Bronx, NY, USA; ${ }^{8}$ Fred Hutchinson Cancer Research Center, Seattle, WA, USA; ${ }^{9}$ Department of Social and Preventive Medicine, University at Buffalo, Buffalo, NY, USA; ${ }^{10}$ George Washington University Medical Center, Washington, DC, USA and ${ }^{11}$ HealthPartners Institute for Education and Research, Box 1524, Mailstop, 21111R, Minneapolis, MN, USA

Background: The objective of this study was to assess the impact of pre-existing diabetes on breast cancer prognosis.

Methods: Women ( $n=2833$ ) with centrally confirmed invasive breast cancer in the Women's Health Initiative, who were linked to Medicare claims data (CMS) were followed from the date of breast cancer diagnosis to date of death or 20 September 2013. Information on diabetes was identified through the CMS Chronic Condition Warehouse algorithm. Cox proportional hazard regression was used to estimate adjusted hazard ratios for overall mortality. A competing risks model (proportional subdistribution) model was used to estimate hazard ratios for breast cancer-specific mortality.

Results: Women with diabetes were more likely to have factors related to delayed diagnosis (less recent mammograms, and more advanced cancer stage) and were less likely to receive radiation therapy. Compared with women without diabetes, women with diabetes had significantly increased risk of overall mortality $(\mathrm{HR}=1.57,95 \% \mathrm{Cl}: 1.23-2.01)$ and had nonsignificantly increased risk for breast cancer-specific mortality ( $\mathrm{HR}=1.36,95 \% \mathrm{Cl}: 0.86-2.15)$ before adjustment for factors related to delayed diagnosis and treatment. Adjustment for these factors resulted in a little change in the association of diabetes with overall mortality risk, but further attenuated the point estimate for breast cancer-specific mortality.

Conclusions: Our study provides additional evidence that pre-existing diabetes increases the risk of total mortality among women with breast cancer. Very large studies with data on breast cancer risk factors, screening and diagnostic delays, treatment choices, and the biological influence of diabetes on breast cancer will be needed to determine whether diabetes also increases the risk for breast cancer-specific mortality.

A large body of epidemiologic evidence suggests that people with diabetes have a significantly higher risk of breast cancer incidence (Larsson et al, 2007; Liao et al, 2011; Boyle et al, 2012) than their nondiabetic counterparts (Lipscombe et al, 2008;
Schrauder et al, 2010; Erickson et al, 2011; Kaplan et al, 2012). Likewise, women with breast cancer who have diabetes have higher mortality than women with breast cancer who do not have diabetes. However, the few studies (Fleming et al, 1999;

*Correspondence: Dr J Luo; E-mail: juhluo@indiana.edu

Received 21 April 2015; revised 10 June 2015; accepted 12 June 2015; published online 9 July 2015

(c) 2015 Cancer Research UK. All rights reserved 0007-0920/15 
Srokowski et al, 2009; Liu et al, 2012) that have examined the impact of diabetes on breast cancer-specific mortality have reported inconsistent results. Thus, more definitive studies are needed to clarify whether the higher overall mortality seen in breast cancer patients with diabetes compared with those without diabetes is related to a poorer prognosis specific to breast cancer or due to risk of mortality from other causes including their diabetes (competing risk).

Diabetes may also have indirect adverse effects on cancer outcomes by influencing decisions regarding cancer screening, diagnosis, or treatment by patients or providers. Research has documented underuse of breast cancer screening among women with diabetes compared with those without diabetes (Lipscombe et al, 2005; McBean and $\mathrm{Yu}, 2007$ ), which may lead to delayed diagnosis. In addition, people with diabetes may receive less aggressive cancer therapies due to their comorbidities (Srokowski et al, 2009; van de Poll-Franse et al, 2007), which may lead to worse prognosis.

Recently, we used the Women's Health Initiative (WHI), a large prospective cohort study, to address the impact of diabetes on breast cancer prognosis, and found that diabetes was associated with total mortality, but was not associated with breast cancerspecific mortality (Luo et al, 2014). However, two main limitations of that study were, one, that diabetes was limited to self-report, and two, information on cancer treatment in the WHI was not available. In this study, we took advantage of a new linkage between the WHI and Medicare claims data (CMS) to overcome these limitations and reanalyse the impact of pre-existing diabetes on prognosis of patients with breast cancer.

\section{METHODS}

Women's Health Initiative linked with CMS data. The WHI provides ongoing follow-up of an ethnically and geographically diverse, multicenter clinical trial (CT), and observational study (OS) designed to address major causes of morbidity and mortality in postmenopausal women. In brief, between September 1993 and December 1998, the WHI enroled 161808 postmenopausal women aged 50-79 years at 40 clinical centres throughout the United States. The WHI CT follow-up ended on 31 March 2005 and observational follow-up for both the CT and OS continued among participants consenting to the WHI Extension 1 (2005-2010) and subsequently to WHI Extension 2 (2010-2015). Details of the scientific rationale, eligibility requirements, and baseline characteristics of the participants in the WHI have been published elsewhere (Women's Health Initiative Study Group, 1998). All participants in the WHI gave informed consent. Consent rates to the WHI Extensions were 82.4\% for CT and $72.9 \%$ for OS for the first extension (2005-2010), and $85.2 \%$ for CT and $88.2 \%$ for OS for the second extension (2010-2015) (Women's Health Initiative, 2015). The study was overseen by IRBs at all 40 clinical centres and at the coordinating center, as well as by a data safety and monitoring board.

Medicare provides electronic records of payments for a wide range of inpatient and outpatient health care services. The data are an established population-based source of detailed health information on the elderly (ages 65 years or older). The WHI has linked Medicare data to WHI participants who are Medicare beneficiaries, with a $99 \%$ success rate for perfect (96.4\%) and fuzzy $(2.3 \%)$ matching among women with a valid social security number. Medicare data (inpatient, outpatient, home health, carrier, hospice, and durable medical equipment) on WHI participants from 1991 to 2013 was used for this study.

Follow-up and ascertainment of breast cancer cases. Incident breast cancer cases were identified by questionnaires (administered every 6 months in the CT through 2005, and annually in the OS and in the CT after 2005), with all reported cases confirmed by medical record review. All primary breast cancer cases were then coded centrally in accordance with the Surveillance Epidemiology and End Results coding guidelines. The breast cancer stage was categorised as: in situ, localized (confined to primary site); regional (spread to regional lymph nodes); distant (cancer has metastasised); or unknown (unstaged). Other tumour characteristics that are available in the WHI database include tumour size, positive lymph nodes, tumour grade, histology, oestrogen receptor status, progesterone receptor status, and HER2 status.

Study population. All invasive breast cancer cases identified in both WHI CT and OS were considered in the study. As of 20 September 2013, there were a total of 10911 breast cancer cases identified in the WHI. We excluded cases of breast cancer in situ (1970 women), breast cancers with missing information on stage (107 women), 713 women with prevalent cancer of any type at baseline (other than nonmelanoma skin cancer), and 13 type 1 diabetes cases (identified by self-report of being told of a diabetes diagnosis at 21 years of age or younger). A total of 8108 cases were left for linkage with CMS data.

Further, inclusion and exclusion criteria included women who: (1) were aged 65 years or older at diagnosis to be linked to CMS data; (2) were continuously enroled in fee-for-service Medicare Parts A and B and were not enroled in an HMO for one year before cancer diagnosis and 6 months after cancer diagnosis to yield a period of 1 -year prior diagnosis during which to ascertain claims for diabetes and 6 months ahead for cancer treatment; (3) did not have end stage renal disease (ESRD); and (4) survived at least 6 months after breast cancer diagnosis. After implementing these criteria, 2833 invasive breast cancer cases remained for analysis.

\section{Measurements}

Outcomes. Overall mortality and breast cancer-specific mortality were considered as the outcomes. Causes of death was classified by trained physician adjudicators based on available documents that included death certificate, medical records, and information from next of kin. Overall mortality was defined as from any cause among women with breast cancer, whereas the breast cancer-specific mortality was defined as death attributed to breast cancer among women with breast cancer.

Diabetes status. We adapted an algorithm developed for the Chronic Condition Data Warehouse by the CMS (CCW, 2015) to identify pre-existing diabetes. Diabetes status was determined on the basis of either a single inpatient claim or at least two outpatient claim diagnoses that were made $>30$ days apart with the International Classification of Disease, 9th Revision, Clinical Modification (ICD-9-CM) diagnosis code of 250.xx during the 1 year before cancer diagnosis. The algorithm we used has been validated both in the WHI and other populations (Hebert et al, 1999; Jackson et al, 2013).

Cancer treatment. The cancer treatment information was determined using CMS data. We categorised surgery for breast cancer as no surgery, breast conserving surgery, and mastectomy. We also identified whether women had chemotherapy (yes, no), and whether women had radiation (yes, no) from CMS data. All treatment codes were based on standard codes that take into account changes over the study course in location of care and specific codes used for reimbursement (see Supplementary Table 1 for all codes we used).

Comorbidity. The NCI combined comorbidity index score proposed by Klabunde et al (2007) using conditions identified by Charlson et al (1987) was used to measure comorbidity based on Medicare claims data. The NCI index (Klabunde et al, 2000) uses weights derived from comorbid conditions identified in either 
Medicare inpatient or outpatient claims into a single comorbidity index. Diabetes was removed from the NCI comorbidity index for this analysis so that the resulting measure quantifies noncancer, nondiabetes comorbidity. ICD-9-CM diagnostic codes recorded in Medicare claims for the period 1 year before the breast cancer diagnosis were searched to create this comorbidity index.

Demographics, breast cancer risk factors, and other covariates. Other covariates obtained from WHI sources included age at diagnosis, race/ethnicity, education level, body mass index (BMI), physical activity, alcohol intake, family history of cancer among females, total daily energy intake, per cent of daily dietary calories from fat, fruit and vegetable intake, history of hormone therapy use, and participation in study cohorts (participation in OS or CTs, and different treatment assignments for all three clinical trials). Other than age at breast cancer diagnosis, and different treatment assignments, all other information was ascertained at enrolment into WHI. During the baseline (enrolment) visit, trained and certified staff performed anthropometric measurements, including height, and weight. The BMI was calculated as weight in $\mathrm{kg}$ divided by the square of height in $\mathrm{m}$. Dietary intake was obtained by using a validated food frequency questionnaire based on instruments previously used in large-scale dietary intervention trials. Other covariates in the WHI were obtained by interview or by self-report using standardised questionnaires. Table 1 shows whether the variables are continuous or categorical.

Statistical analysis. The distribution of the study subjects by baseline characteristics and by breast tumour characteristics were compared between women with and without diabetes. Chi-square tests were used to evaluate differences for categorical covariates, and $t$-tests were used for continuous variables.

The Kaplan-Meier method was used to estimate survival curves for overall mortality and breast cancer-specific mortality stratified by diabetes status. Survival time was measured as the days from date of breast cancer diagnosis until death or 20 September 2013, whichever came first. For overall mortality analyses, we treated the data of women alive at the end of follow-up as censored observations.

Multivariable Cox proportional hazards regression models were then used to estimate adjusted relative hazard ratios for overall mortality in relation to diabetes status after adjusting for potential confounders. The proportional subdistribution hazard model proposed by Fine and Gray (1999) was used to estimate hazard ratios for breast cancer-specific mortality associated with diabetes status by accounting for nonbreast cancer mortality as a competing risk. In all multivariable models, potential confounders included variables listed in Table 1 . All models were stratified by different study sub-cohorts (participation in OS or CTs, and different treatment assignments for all three clinical trials). To examine different potential influences of diabetes on cancer prognosis, we performed analyses by adjusting for different levels of covariates: (1) adjusting for demographics and traditional breast cancer risk factors; (2) further adjusting for factors that could be related to delayed diagnosis, such as mammographic screening and cancer stage; (3) further adjusting for cancer treatments.

\section{RESULTS}

Of a total of 2833 women diagnosed with invasive breast cancer, 299 (10.6\%) had pre-existing diabetes. Baseline characteristics by diabetes status are shown in Table 1. Compared with women without diabetes, women with diabetes were significantly more likely to be members of non-White race/ethnicity groups, to be heavier, to be physically inactive, to be current non-drinkers, to be less educated, have high dietary energy intake and high per cent
Table 1. Baseline characteristics of 2833 invasive breast cancer by diabetes status identified from CMS data

\begin{tabular}{|c|c|c|c|}
\hline & $\begin{array}{l}\text { No diabetes } \\
\text { (2534 patients) }\end{array}$ & $\begin{array}{c}\text { Diabetes } \\
\text { (299 patients) }\end{array}$ & $P$-value \\
\hline $\begin{array}{l}\text { Age at breast cancer } \\
\text { diagnosis (mean } \\
\text { (s.d.)) }\end{array}$ & $73.2(5.4)$ & $73.4(5.3)$ & 0.69 \\
\hline $\begin{array}{l}\text { White (not of } \\
\text { Hispanic origin) (\%) }\end{array}$ & 2339 (92.3) & 248 (82.9) & $<0.0001$ \\
\hline $\begin{array}{l}\text { BMI at baseline } \\
\text { (mean (s.d.), } \mathrm{kg} \mathrm{m}^{-2} \text { ) }\end{array}$ & $27.6(5.4)$ & $32.1(6.2)$ & $<0.0001$ \\
\hline $\begin{array}{l}\text { Physical Activity } \\
\text { (METs per week, } \\
\text { mean (s.d.)) }\end{array}$ & $12.7(13.0)$ & $9.3(10.4)$ & $<0.0001$ \\
\hline Alcohol use (\%) & & & $<0.0001$ \\
\hline $\begin{array}{l}\text { Nondrinker } \\
\text { Past drinker } \\
\text { Current drinker }\end{array}$ & $\begin{array}{r}224(8.8) \\
379(15.0) \\
1913(75.5)\end{array}$ & $\begin{array}{r}51(17.1) \\
80(26.8) \\
165(55.2)\end{array}$ & \\
\hline Education (\%) & & & 0.0002 \\
\hline $\begin{array}{l}\text { High school diploma } \\
\text { or less } \\
\text { Some college or } \\
\text { technical training } \\
\text { College or higher }\end{array}$ & $\begin{array}{l}443(17.5) \\
917(36.2) \\
1162(45.9)\end{array}$ & $\begin{array}{l}77(25.8) \\
118(39.5) \\
102(34.1)\end{array}$ & \\
\hline \multicolumn{4}{|l|}{ Dietary intake } \\
\hline $\begin{array}{l}\text { Dietary energy (kcal) } \\
\text { Percent calories } \\
\text { from fat } \\
\text { Daily fruit } \\
\text { consumption (med } \\
\text { portion) } \\
\text { Daily vegetable } \\
\text { consumption (med } \\
\text { portion) }\end{array}$ & $\begin{array}{c}1636(624.7) \\
33(8.1) \\
1.9(1.2)\end{array}$ & $\begin{array}{c}1750(864.5) \\
34(8.3) \\
2.0(1.3)\end{array}$ & $\begin{array}{l}0.03 \\
0.04 \\
0.6\end{array}$ \\
\hline $\begin{array}{l}\text { Prior hormone use at } \\
\text { baseline (\%) }\end{array}$ & & & $<0.0001$ \\
\hline $\begin{array}{l}\text { No } \\
\text { OEstrogen alone } \\
\text { OEstrogen plus } \\
\text { progestin } \\
\text { Mixed }\end{array}$ & $\begin{array}{r}1042(41.1) \\
705(27.8) \\
606(23.9) \\
181(7.1)\end{array}$ & $\begin{aligned} & 156(52.2) \\
& 90(30.1) \\
&> 11(\sim) \\
&<11(\sim)\end{aligned}$ & \\
\hline Comorbidity & & & $<0.0001$ \\
\hline $\begin{array}{l}0 \\
1 \\
2 \\
3+\end{array}$ & $\begin{array}{c}2145(84.7) \\
313(12.4) \\
57(2.2) \\
19(0.8)\end{array}$ & $\begin{aligned} & 220(73.6) \\
& 49(16.4) \\
& 16(5.4) \\
& 14(4.7)\end{aligned}$ & \\
\hline $\begin{array}{l}\text { Family history of } \\
\text { cancer among } \\
\text { female relatives (\%) }\end{array}$ & $1333(52.6)$ & $163(54.5)$ & 0.31 \\
\hline \multicolumn{4}{|c|}{$\begin{array}{l}\text { Abbreviation: MET = Metabolic equivalent task. The cell sizes were suppressed for } \\
\text { confidentiality reasons per the Medicare data usage agreement. Some of categories did not } \\
\text { exactly sum up to the total number because of missing values. }\end{array}$} \\
\hline
\end{tabular}

calories from fat, to not use hormones or to use oestrogen alone, and to have a greater number of comorbid conditions. However, there was no substantial difference between the diabetes group and those without diabetes with respect to age at diagnosis, daily fruit or vegetable consumption, or family history of cancer among female relatives (Table 1).

Regarding tumour characteristics, compared with women without diabetes, women with diabetes were more likely to have more advanced tumour stage, to have HER2-negative tumours, and to have a longer interval from the last mammogram to breast cancer diagnosis (Table 2). There were no statistically significant differences in other tumour characteristics, including tumour size, lymph nodes, grade, oestrogen, progesterone receptor status, and chemotherapy. Women with diabetes were less likely to receive 
Table 2. Breast cancer characteristics (a total of 2833 invasive breast cancer) by diabetes status identified from CMS data

\begin{tabular}{|c|c|c|c|}
\hline & $\begin{array}{l}\text { No diabetes } \\
\text { (2534 patients) }\end{array}$ & $\begin{array}{c}\text { Diabetes } \\
\text { (299 patients) }\end{array}$ & $P$-value ${ }^{a}$ \\
\hline Stage & & & 0.001 \\
\hline $\begin{array}{l}\text { Local } \\
\text { Regional } \\
\text { Advanced }\end{array}$ & $\begin{array}{r}1976(78.0) \\
534(21.1) \\
24(1.0)\end{array}$ & $\begin{aligned} & 216(72.2) \\
> & =11(\sim) \\
< & 11(\sim)\end{aligned}$ & \\
\hline Tumour size, mm & & & 0.13 \\
\hline $\begin{array}{l}\leq 5 \\
>5-10 \\
>10-20 \\
\geq 20\end{array}$ & $\begin{array}{l}319(12.6) \\
691(27.3) \\
822(32.4) \\
702(27.7)\end{array}$ & $\begin{array}{r}28(9.4) \\
73(24.4) \\
100(33.4) \\
98(32.8)\end{array}$ & \\
\hline $\begin{array}{l}\text { Positive lymph } \\
\text { nodes }\end{array}$ & & & 0.17 \\
\hline $\begin{array}{l}\text { No } \\
\text { Yes }\end{array}$ & $\begin{array}{r}1977(78.0) \\
513(20.2)\end{array}$ & $\begin{array}{r}219(73.2) \\
73(24.4)\end{array}$ & \\
\hline Grade & & & 0.09 \\
\hline $\begin{array}{l}\text { Well differentiated } \\
\text { Moderately } \\
\text { differentiated } \\
\text { Poorly differentiated } \\
\text { Anaplastic } \\
\text { Missing }\end{array}$ & $\begin{array}{c}682(26.9) \\
1014(40.0) \\
\\
567(22.4) \\
55(2.2) \\
216(8.5)\end{array}$ & $\begin{array}{r}71(23.8) \\
144(48.2) \\
\\
55(18.4) \\
<11(\sim) \\
>11(\sim) \\
\end{array}$ & \\
\hline $\begin{array}{l}\text { OEstrogen } \\
\text { receptor status }\end{array}$ & & & 0.75 \\
\hline $\begin{array}{l}\text { Positive } \\
\text { Negative } \\
\text { Borderline } \\
\text { Unknown/not done/ } \\
\text { missing }\end{array}$ & $\begin{array}{l}2042(80.6) \\
346(13.7) \\
<11(\sim) \\
>11(\sim)\end{array}$ & $\begin{aligned} & 239(79.9) \\
& 40(13.4) \\
&<11(\sim) \\
&>11(\sim)\end{aligned}$ & \\
\hline $\begin{array}{l}\text { Progesterone } \\
\text { receptor status }\end{array}$ & & & 0.66 \\
\hline $\begin{array}{l}\text { Positive } \\
\text { Negative } \\
\text { Borderline } \\
\text { Unknown/not done/ } \\
\text { missing }\end{array}$ & $\begin{array}{c}1736(68.5) \\
640(25.3) \\
12(0.5) \\
146(5.8)\end{array}$ & $\begin{aligned} 200(66.9) \\
75(25.1) \\
<11(\sim) \\
>11(\sim)\end{aligned}$ & \\
\hline HER2 & & & 0.02 \\
\hline $\begin{array}{l}\text { Positive } \\
\text { Negative } \\
\text { Borderline } \\
\text { Unknown/not done/ } \\
\text { missing }\end{array}$ & $\begin{array}{c}300(11.8) \\
1686(66.5) \\
20(0.8) \\
528(20.8)\end{array}$ & $\begin{aligned} & 24(8.0) \\
& 229(76.6) \\
< & 11(\sim) \\
> & 11(\sim)\end{aligned}$ & \\
\hline $\begin{array}{l}\text { Mammography } \\
\text { interval }\end{array}$ & & & 0.02 \\
\hline $\begin{array}{l}<1 \text { year } \\
1 \text { to }<2 \text { years } \\
2 \text { to }<5 \text { years } \\
5 \text { or more years or } \\
\text { never }\end{array}$ & $\begin{array}{r}1316(51.9) \\
387(15.3) \\
428(16.9) \\
403(15.9)\end{array}$ & $\begin{array}{r}132(44.2) \\
48(16.1) \\
71(23.8) \\
48(16.1)\end{array}$ & \\
\hline Surgery & & & 0.10 \\
\hline $\begin{array}{l}\text { No surgery } \\
\text { Breast conserving } \\
\text { surgery (BCS) } \\
\text { Mastectomy }\end{array}$ & $\begin{array}{c}118(4.7) \\
1648(65.0) \\
768(30.3)\end{array}$ & $\begin{array}{c}18(6.0) \\
176(58.9) \\
105(35.1)\end{array}$ & \\
\hline Chemotherapy (yes) & $565(22.3)$ & $72(24.1)$ & 0.48 \\
\hline Radiation (yes) & $1486(58.6)$ & $152(50.8)$ & 0.01 \\
\hline \multicolumn{4}{|c|}{$\begin{array}{l}\text { ( ) The cell sizes were suppressed for confidentiality reasons per the Medicare data usage } \\
\text { agreement. } \\
\mathbf{a}^{2} \text {-test included missing category. }\end{array}$} \\
\hline
\end{tabular}

radiation treatment than women without diabetes. Women with diabetes had less breast-conserving surgery and were more likely to have mastectomies than women without diabetes, although the differences were not statistically significant.
Figure 1 shows the Kaplan-Meier unadjusted survival curves stratified by diabetes status for overall mortality (Figure 1A) and for breast cancer-specific mortality and noncancer related mortality from the Fine-Gray competing risk analysis (Figure 1B). There was a significant difference between women without and with diabetes for overall mortality $(P<0.0001)$ and for breast cancer-specific mortality $(P=0.01)$ by the log-rank test.

Table 3 shows unadjusted and adjusted hazard ratios for mortality in relation to diabetes status. Compared with women without diabetes, women with diabetes had significantly increased risk of overall mortality after adjusting for demographic and traditional risk factors for breast cancer ( Model 1, HR $=1.5795 \%$, CI: 1.23-2.01), as well as after further adjusting for factors related to delayed detection, cancer treatments, and tumour markers (Model 3, HR $=1.46,95 \%$ CI: 1.12-1.86). Women with diabetes had a nonsignificantly increased risk for breast cancer-specific mortality $(\mathrm{HR}=1.36,95 \% \mathrm{CI}: 0.86-2.15)$ after adjusting for demographic and traditional risk factors for breast cancer. Further adjusting for factors that are related to delayed diagnosis (screening and stage) attenuated the association between diabetes and breast cancer-specific mortality (Model 2, HR $=1.13,95 \%$ CI 0.70-1.84). Further adjustment for cancer treatments and tumour markers yielded similar results (Model 3, HR $=1.32$, 95\% CI: 0.80-2.17).

Finally, we conducted several sensitivity analyses by (1) changing the time window from looking back 1 year to looking back 2 years before cancer diagnosis (data not shown); (2) using diabetes based on self-reported information from WHI instead of using diabetes identified in the CMS (data not shown); (3) using conventional epidemiology methods (Cox proportional hazards) to analyse breast cancer-specific mortality by considering the dates of death from causes other than breast cancer as censored observations (Table 3). All results were similar to those presented here.

\section{DISCUSSION}

Our study observed that pre-existing diabetes is associated with increased risk of overall mortality among women with breast cancer that persisted after adjustment for potential confounders. Pre-existing diabetes was significantly associated with increased unadjusted risk of breast cancer-specific mortality. After adjustment for demographic and breast cancer risk factors, increased breast cancer-specific mortality for women with diabetes did not reach statistical significance. Our data also show that women with diabetes were less likely to have recent mammograms and receive radiation therapy, and were more likely to be diagnosed at an advanced tumour stage. Adjustment for these factors further attenuated the excess risk of breast cancer mortality associated with diabetes.

The differences in the tumour characteristics (especially in tumour stage) between women with and without diabetes may explain some of the differences in treatment, because women with less advanced tumour stage are more likely to have breastconserving surgery and are more likely to receive radiation treatment. Our previous publication on this topic using WHI data (Luo et al, 2014) similarly found that total mortality risk, but not breast cancer-specific mortality risk, was higher for women with pre-existing diabetes. The contribution of the current paper demonstrates that this pattern persists when Medicare claims data are available to confirm diabetes diagnosis over self-report, and when we can better account for cancer treatment variables and other comorbidity. The previous publication showed a negative, but nonsignificant relationship between diabetes and breast cancerspecific mortality; in the current paper the finding is positive but nonsignificant. The positive but nonsignificant finding in the current paper could reflect the true state of affairs (no association) 
A

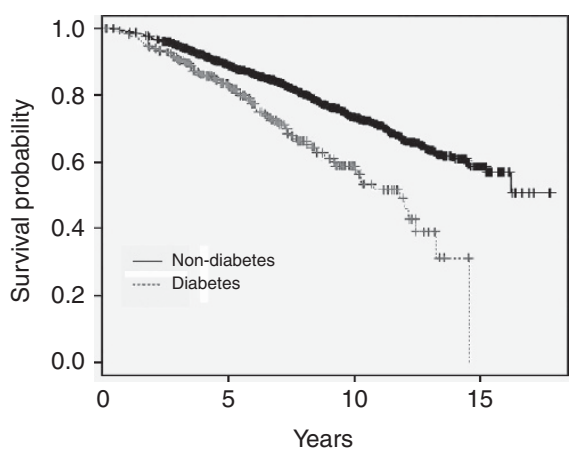

B For breast cancer-specific mortality

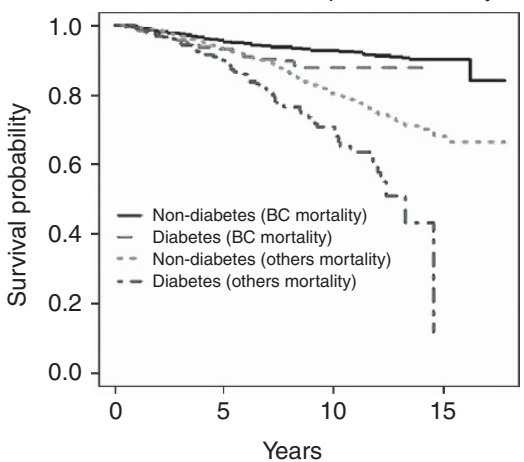

Figure 1. Kaplan-Meier survival probability stratified by diabetes status for overall mortality (A) and breast cancer-specific mortality and non-cancer related mortality from the Fine-Gray competing risk analysis (B). BC, breast cancer.

Table 3. Effect of pre-existing diabetes on total and breast cancer specific mortality in women with breast cancer

\begin{tabular}{|c|c|c|c|c|c|c|}
\hline & & \multicolumn{5}{|c|}{ Hazard ratio $(95 \% \mathrm{Cl})$} \\
\hline & Cases (death) & $\begin{array}{l}\text { Model-without } \\
\text { adjustment }\end{array}$ & $\begin{array}{l}\text { Model-only } \\
\text { adjusting for age }\end{array}$ & Model $1^{a}$ & Model $2^{b}$ & Model $3^{c}$ \\
\hline \multicolumn{7}{|c|}{ Total mortality } \\
\hline $\begin{array}{l}\text { Diabetes (no) } \\
\text { Diabetes (yes) }\end{array}$ & $\begin{array}{c}2534(587) \\
299(94)\end{array}$ & $\begin{array}{c}\text { Reference } \\
1.88(1.51-2.34)\end{array}$ & $\begin{array}{c}\text { Reference } \\
1.90(1.53-2.36)\end{array}$ & $\begin{array}{c}\text { Reference } \\
1.57(1.23-2.01)\end{array}$ & $\begin{array}{c}\text { Reference } \\
1.47(1.15-1.89)\end{array}$ & $\begin{array}{c}\text { Reference } \\
1.46(1.12-1.86)\end{array}$ \\
\hline \multicolumn{7}{|c|}{ Breast cancer specific mortality using traditional method } \\
\hline $\begin{array}{l}\text { Diabetes (no) } \\
\text { Diabetes (yes) }\end{array}$ & $\begin{array}{c}2534(167) \\
299(27)\end{array}$ & $\begin{array}{c}\text { Reference } \\
1.70(1.13-2.56)\end{array}$ & $\begin{array}{c}\text { Reference } \\
1.73(1.15-2.60)\end{array}$ & $\begin{array}{c}\text { Reference } \\
1.47(0.93-2.31)\end{array}$ & $\begin{array}{c}\text { Reference } \\
1.18(0.73-1.92)\end{array}$ & $\begin{array}{c}\text { Reference } \\
1.39(0.84-2.29)\end{array}$ \\
\hline \multicolumn{7}{|c|}{ Breast cancer specific mortality using competing risk model } \\
\hline $\begin{array}{l}\text { Diabetes (no) } \\
\text { Diabetes (yes) }\end{array}$ & $\begin{array}{c}2534(167) \\
299(27) \\
\end{array}$ & $\begin{array}{c}\text { Reference } \\
1.58(1.05-2.37)\end{array}$ & $\begin{array}{c}\text { Reference } \\
1.60(1.07-2.41)\end{array}$ & $\begin{array}{c}\text { Reference } \\
1.36(0.86-2.15)\end{array}$ & $\begin{array}{c}\text { Reference } \\
1.13(0.70-1.84)\end{array}$ & $\begin{array}{c}\text { Reference } \\
1.32(0.80-2.17)\end{array}$ \\
\hline \multicolumn{7}{|c|}{ 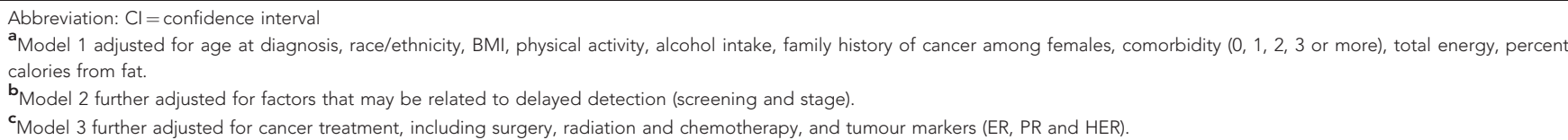 } \\
\hline
\end{tabular}

or could reflect a trend towards a significant risk that we could not detect due to limited statistical power.

There are a number of possible explanations for nonassociation between pre-existing diabetes and breast cancer-specific mortality. First, women who are diagnosed with diabetes may adopt positive lifestyle changes or receive diabetes therapies that reduce breast cancer-specific mortality risk (Ben Sahra et al, 2011). Many clinical and preclinical studies suggest that metformin has antitumour activity, although evidence of a protective effect of metformin in early breast cancer has not been proven and clinical trials are under way (Rizos and Elisaf, 2013; Miranda et al, 2014). Second, effective treatments for breast cancer, such as adding trastuzumab to adjuvant chemotherapy or chemotherapy with anthracycline are associated with increased risk of cardiomyopathy and congestive heart failure (Seidman et al, 2002), which may increase the risk of dying from cardiovascular disease, especially in patients with diabetes (Serrano et al, 2012). In this case, the increased nonbreast cancer mortality cannot be separated from the consequences of breast cancer treatment. Third, there may also be a degree of misclassification when assigning cause of death; because of the well-recognised clinical link between diabetes and cardiovascular complications, even patients with advanced cancer may be assigned cardiovascular diseases as a cause of death. Finally, our result may be owing to limited study power to detect a significant association. The confidence intervals are relatively wide and may not exclude a modest increase in breast cancer-specific mortality.

The strengths of the study include comprehensive data on demographic variables, breast cancer risk factors, tumour characteristics and physician-adjudicated causes of death provided in the WHI, and cancer treatment provided in the CMS data. The WHI-CMS-linked data provides a rich resource with which to elucidate the potential causes for increased mortality following breast cancer in diabetic women. However, several limitations also deserve mention. First, although the algorithm we used to identify diabetes in the CMS was validated (Hebert et al, 1998; Gorina and Kramarow, 2011), some degree of misclassification of the exposure may remain. This misclassification may have biased our effect estimates towards the null. Second, the statistical power for breast cancer-specific mortality analysis may have been limited owing to the relatively small number of breast cancer deaths. Third, claims data are not available before the age 65 years or for women enroled in Medicare managed care plans, which limits our analysis to patients who are at least 66 years old; thus, our findings may not extend to younger patients or to those enroled in Medicare managed care plans. In addition, we had no Medicare Drug data (Part D), so that we do not have information regarding potential chemotherapy (e.g. trastuzumab) with cardiac toxicity or adjuvant endocrine therapy, where questions have been raised regarding aromatase inhibitors role on cardiac outcomes. Other limitations include lack of information regarding glucose control and diabetes progression.

In conclusion, our study provides additional evidence that pre-existing diabetes is associated with increased risk of total mortality among women with breast cancer. The increased total mortality associated with diabetes may be mainly driven by increased risk of dying from diseases other than breast cancer. Very large studies with data on breast cancer risk factors, screening and 
diagnostic delays, treatment choices, and the biological influence of diabetes on breast cancer will be needed to determine whether diabetes also increases the risk for breast cancer-specific mortality.

\section{ACKNOWLEDGEMENTS}

Research reported in this publication was supported by the National Cancer Institute of the National Institutes of Health under Award Number R15CA179463. The WHI program is funded by the National Heart, Lung, and Blood Institute, National Institutes of Health, U.S. Department of Health and Human Services through contracts HHSN268201100046C, HHSN268201 100001C, HHSN268201100002C, HHSN268201100003C, HHSN $268201100004 \mathrm{C}$, and HHSN271201100004C. We also request that you consult www.whi.org for exact wording if you include a description of the WHI trials in your manuscript. A short list of WHI investigators appears in the Supplementary Data Online.

\section{CONFLICT OF INTEREST}

The authors declare no conflict of interest.

\section{DISCLAIMER}

The content is solely the responsibility of the authors and does not necessarily represent the official views of the National Institutes of Health.

\section{REFERENCES}

Ben Sahra I, Regazzetti C, Robert G, Laurent K, Le Marchand-Brustel Y, Auberger P, Tanti JF, Giorgetti-Peraldi S, Bost F (2011) Metformin, independent of AMPK, induces mTOR inhibition and cell-cycle arrest through REDD1. Cancer Res 71(13): 4366-4372.

Boyle P, Boniol M, Koechlin A, Robertson C, Valentini F, Coppens K, Fairley LL, Boniol M, Zheng T, Zhang Y, Pasterk M, Smans M, Curado MP, Mullie P, Gandini S, Bota M, Bolli GB, Rosenstock J, Autier P (2012) Diabetes and breast cancer risk: a meta-analysis. Br J Cancer 107(9): 1608-1617.

CCW (2015) Chronic condition data warehouse https://www.ccwdata.org/ web/guest/condition-categoriesAccessed on 06 January 2015.

Charlson ME, Pompei P, Ales KL, MacKenzie CR (1987) A new method of classifying prognostic comorbidity in longitudinal studies: development and validation. J Chronic Dis 40(5): 373-383.

Erickson K, Patterson RE, Flatt SW, Natarajan L, Parker BA, Heath DD, Laughlin GA, Saquib N, Rock CL, Pierce JP (2011) Clinically defined type 2 diabetes mellitus and prognosis in early-stage breast cancer. J Clin Oncol 29(1): 54-60.

Fine JP, Gray RJ (1999) A proportional hazards model for the subdistribution of a competing risk. J Am Stat Assoc 94(446): 496-509.

Fleming ST, Rastogi A, Dmitrienko A, Johnson KD (1999) A comprehensive prognostic index to predict survival based on multiple comorbidities: a focus on breast cancer. Med Care 37(6): 601-614.

Gorina Y, Kramarow EA (2011) Identifying chronic conditions in Medicare claims data: evaluating the Chronic Condition Data Warehouse algorithm. Health Serv Res 46(5): 1610-1627.

Hebert PL, Engelgau MM, Geiss LS, Tierney E, Riley G, Mcbean AM (1998) Identifying diabetes in the Medicare population using Medicare claims data. Diabetes 47: A187-A187.

Hebert PL, Geiss LS, Tierney EF, Engelgau MM, Yawn BP, McBean AM (1999) Identifying persons with diabetes using Medicare claims data. Am J Med Qual 14: 270-277.
Jackson JM, Defor TA, Crain AL, Kerby T, Strayer L, Lewis CE, Whitlock E, Williams S, Bonds DE, Vitolins MZ, Rodabough RJ, Margolis KL (2013) Self-reported diabetes is a valid outcome in pragmatic clinical trials and observational studies. J Clin Epidemiol 66: 349-350.

Kaplan MA, Pekkolay Z, Kucukoner M, Inal A, Urakci Z, Ertugrul H, Akdogan R, Firat U, Yildiz I, Isikdogan A (2012) Type 2 diabetes mellitus and prognosis in early stage breast cancer women. Med Oncol 29(3): 1576-1580.

Klabunde CN, Legler JM, Warren JL, Baldwin LM, Schrag D (2007) A refined comorbidity measurement algorithm for claims-based studies of breast, prostate, colorectal, and lung cancer patients. Ann Epidemiol 17(8): 584-590.

Klabunde CN, Potosky AL, Legler JM, Warren JL (2000) Development of a comorbidity index using physician claims data. J Clin Epidemiol 53(12): $1258-1267$.

Larsson SC, Mantzoros CS, Wolk A (2007) Diabetes mellitus and risk of breast cancer: a meta-analysis. Int J Cancer 121(4): 856-862.

Liao S, Li J, Wei W, Wang L, Zhang Y, Li J, Wang C, Sun S (2011) Association between diabetes mellitus and breast cancer risk: a meta-analysis of the literature. Asian Pac J Cancer Prev 12(4): 1061-1065.

Lipscombe LL, Goodwin PJ, Zinman B, McLaughlin JR, Hux JE (2008) The impact of diabetes on survival following breast cancer. Breast Cancer Res Treat 109(2): 389-395.

Lipscombe LL, Hux JE, Booth GL (2005) Reduced screening mammography among women with diabetes. Arch Intern Med 165(18): 2090-2095.

Liu XD, Ji JG, Sundquist K, Sundquist J, Hemminki K (2012) The impact of type 2 diabetes mellitus on cancer-specific survival A follow-up study in Sweden. Cancer 118(5): 1353-1361.

Luo J, Virnig B, Hendryx M, Wen S, Chelebowski R, Chen C, Rohan T, Tinker L, Wactawski-Wende J, Lessin L, Margolis K (2014) Diabetes, diabetes treatment and breast cancer prognosis. Breast Cancer Res Treat 148(1): 153-162.

McBean AM, Yu XH (2007) The underuse of screening services among elderly women with diabetes. Diabetes Care 30(6): 1466-1472.

Miranda VC, Barroso-Sousa R, Glasberg J, Riechelmann RP (2014) Exploring the role of metformin in anticancer treatments: a systematic review. Drugs Today 50(9): 623-640.

Rizos CV, Elisaf MS (2013) Metformin and cancer. Eur J Pharmacol 705(1-3): 96-108.

Schrauder MG, Fasching PA, Haberle L, Lux MP, Rauh C, Hein A, Bayer CM, Heusinger K, Hartmann A, Strehl JD, Wachter DL, Schulz-Wendtland R, Adamietz B, Beckmann MW, Loehberg CR (2010) Diabetes and prognosis in a breast cancer cohort. J Cancer Res Clin Oncol 137(6): 975-983.

Seidman A, Hudis C, Pierri MK, Shak S, Paton V, Ashby M, Murphy M, Stewart SJ, Keefe D (2002) Cardiac dysfunction in the trastuzumab clinical trials experience. J Clin Oncol 20(5): 1215-1221.

Serrano C, Cortes J, De Mattos-Arruda L, Bellet M, Gomez P, Saura C, Perez J, Vidal M, Munoz-Couselo E, Carreras MJ, Sanchez-Olle G, Tabernero J, Baselga J, Di Cosimo S (2012) Trastuzumab-related cardiotoxicity in the elderly: a role for cardiovascular risk factors. Ann Oncol 23(4): 897-902.

Srokowski TP, Fang S, Hortobagyi GN, Giordano SH (2009) Impact of diabetes mellitus on complications and outcomes of adjuvant chemotherapy in older patients with breast cancer. J Clin Oncol 27(13): 2170-2176.

van de Poll-Franse LV, Houterman S, Janssen-Heijnen MLG, Dercksen MW, Coebergh JWW, Haak HR (2007) Less aggressive treatment and worse overall survival in cancer patients with diabetes: A large population based analysis. Int J Cancer 120(9): 1986-1992.

Women's Health Initiative (2015) https://www.whi.org/about/SitePages/ About\%20WHI.aspx (last accessed 06 January 2015).

Women's Health Initiative Study Group (1998) Design of the Women's Health Initiative clinical trial and observational study. The Women's Health Initiative Study Group. Control Clin Trials 19(1): 61-109.

This work is published under the standard license to publish agreement. After 12 months the work will become freely available and the license terms will switch to a Creative Commons AttributionNonCommercial-Share Alike 4.0 Unported License

Supplementary Information accompanies this paper on British Journal of Cancer website (http://www.nature.com/bjc) 